\title{
Lithium Intoxication: A Possible Interaction with Moxifloxacin
}

\author{
Selvi Kayipmaz, Ali Ercan Altınöz, Nadide Elmas Gülcü Ok \\ Department of Psychiatry, Baskent University Faculty of Medicine, Ankara, Turkey
}

\begin{abstract}
Lithium is a well-known treatment for patients with mood disorders. Intoxication by lithium may be lethal particularly in elderly due to altered pharmacokinetics, renal impairment or multiple drug use. We presented a 74-year-old female patient who had been stabile with lithium carbonate $600 \mathrm{mg} /$ day for 5 years and developed lithium intoxication after bronchiolitis. She presented with altered mental status. The neurological signs resolved slowly after lithium and moxifloxacin were stopped immediately and fluid resuscitation administered. Considering possible drug interactions on elderly patients receiving lithium is essential.
\end{abstract}

KEY WORDS: Drug interactions; Lithium; Moxifloxacin.

\section{INTRODUCTION}

Lithium has been used for more than a half-century and is a well-known and established treatment for patients with mood disorders such as bipolar disorders and recurrent unipolar depression. Therapeutic serum lithium concentrations are between 0.6-1 mmol/L. Serum lithium concentrations above $1.2 \mathrm{mmol} / \mathrm{L}$ may cause intoxication. Because lithium has a narrow therapeutic index, its serum level must be kept within critical limits, particularly in the elderly. ${ }^{1-6)}$ Geriatric population is more at risk of developing lithium intoxication, cause of reduced volume of distribution, decreased age-related glomerular filtration rate; comorbid diseases, and polypharmacy.

Medications which are frequently used in geriatric population, such as angiotensin-converting enzyme (ACE) inhibitors, diuretics, nonsteroidal anti-inflammatory drugs (NSAIDs) may induce lithium toxicity. ${ }^{7)}$

Lithium intoxication may manifest with, gastrointestinal (vomiting, diarrhea), renal (polyuria, polydipsia, acute renal failure), cardiovascular (syncope, dizziness, bradycardia, arrhythmias) and nervous system (drowsi-

\footnotetext{
Received: April 15, 2016/ Revised: June 22, 2016

Accepted: August 3, 2016

Address for correspondence: Selvi Kayipmaz, MD

Department of Psychiatry, Baskent University Faculty of Medicine, 54th Street, Number: 70/3, 064901 Bahcelievler, Ankara, Turkey

Tel: +90-312-203-68-68, Fax: +90-312-223-73-33

E-mail: selviceran@hotmail.com

*This paper was presented as a poster at 8th International Congress on Psychopharmacology \& 4th International Symposium on Child and Adolescent Psychopharmacology (8th ICP - 4th ISCAP) on April 20-24, 2016 in Antalya, Turkey.
}

ness, fatigue, lethargy, confusion, delirium, coma, ataxia, dysarthria, seizures, tremors, myoclonic jerks) symptoms. Lithium intoxication may be lethal, and it should be monitored carefully. ${ }^{8,9)}$

Moxifloxacin is a fluoroquinolone antibiotic agent. ${ }^{10)}$ To the best of our knowledge, lithium poisoning induced by the combined use of moxifloxacin and lithium in psychiatric patients has never been reported. In this case report, we describe a possible interaction between moxifloxacin and lithium in an elderly patient.

\section{CASE}

A 74-year-old woman with a 5-year history of bipolar affective disorder is presented. She started on lithium carbonate $600 \mathrm{mg} /$ day, haloperidol $10 \mathrm{mg} /$ day, risperidone 2 $\mathrm{mg} /$ day at her first manic episode in 2010. After she had a depressive episode in 2011, sertraline $25 \mathrm{mg}$ /day added to treatment and from then until January 2016 her serum lithium concentration ranged from 0.60 to $0.80 \mathrm{mmol} / \mathrm{L}$. She had been maintained on lithium carbonate $300 \mathrm{mg}$ in the morning and $300 \mathrm{mg}$ at night.

She presented to the emergency department with complaints of severe tremor in both hands, myoclonic jerks of the upper extremities, exhaustion, and slurred speech on January 15 th, 2016. On examination, her body temperature was normal and her blood pressure was 110/70 $\mathrm{mmHg}$. Her symptoms began the day after she started using moxifloxacin $400 \mathrm{mg}$ /day for the treatment of bronchiolitis; her serum lithium concentration was $0.8 \mathrm{mEq} / \mathrm{L}$ 10 days before. She did not have vomiting, diarrhea, nys-

(a) This is an Open-Access article distributed under the terms of the Creative Commons Attribution Non-Commercial License (http://creativecommons.org/licenses/by-nc/4.0) which permits unrestricted non-commercial use, distribution, and reproduction in any medium, provided the original work is properly cited. 
tagmus, or dysarthria. On her mental state examination, she was slightly drowsy and disoriented. Her speech was slurred. Her serum lithium concentration was $1.7 \mathrm{mEq} / \mathrm{L}$ (normal laboratory values $0.5-1 \mathrm{mEq} / \mathrm{L}$ ). Physical examination and other laboratory tests in the emergency department revealed no renal impairment or sign of dehydration. Laboratory results were as follows: fasting blood glucose, $88 \mathrm{mg} / \mathrm{dl}$; blood urea nitrogen, $25 \mathrm{mg} / \mathrm{dl}$; creatinine, 0.99 $\mathrm{mg} / \mathrm{dl}$; sodium, $139 \mathrm{mmol} / \mathrm{L}$; potassium, $3.4 \mathrm{mmol} / \mathrm{L}$; calcium, $9.2 \mathrm{mg} / \mathrm{dl}$; alanine aminotransferase, $13 \mathrm{U} / \mathrm{L}$; aspartate aminotransferase, $6 \mathrm{U} / \mathrm{L}$; creatine kinase level (CK), $29 \mathrm{U} / \mathrm{L}$; CK-MB fraction, $1 \mathrm{ng} / \mathrm{ml}$; troponin-I, $0.016 \mathrm{ng} / \mathrm{ml}$; lithium level, $1.7 \mathrm{mEq} / \mathrm{L}$; white blood cell, 7.090/ $\mathrm{l}$; red blood cell, $4.38 \mathrm{M} / \mu \mathrm{l}$; hemoglobin, 12.3 $\mathrm{g} / \mathrm{dl}$; and hematocrit, $39 \%$. Urinalysis results were as follows: density, 1,014; $\mathrm{pH}, 7.5$; protein, 20; glucose, negative; ketone, $0 \mathrm{mg} / \mathrm{dl}$; bilirubin, $0 \mathrm{mg} / \mathrm{dl}$; urobilinogen, 0 $\mathrm{mg} / \mathrm{dl}$; nitrite, negative; and leukocyte, negative.

Neither her cranial magnetic resonance imaging nor electrocardiography (ECG) showed any abnormalities. After ruling out hypoxia, hypoglycemia, hypothermia or hyperthermia, electrolyte disorders, central nervous system infection, head trauma, intracranial bleeding, and neuroleptic malignant syndrome, she was diagnosed with mild-moderate toxicity of lithium.

Lithium and moxifloxacin were stopped immediately; she was administered fluid resuscitation with less than $2 \mathrm{~L}$ of $0.9 \%$ saline solution for 6 hours. After 12 hours, her serum lithium concentration decreased to $0.9 \mathrm{mEq} / \mathrm{L}$, and her tremors and myoclonic jerks were diminished. On the second day, drowsiness and disorientation were still evident, but these remaining neurological signs resolved 1 week later.

\section{DISCUSSION}

Lithium toxicity is a life-threatening situation and particularly prevalent in elderly patients due to altered pharmacokinetics, renal impairment, and multiple drug use. In elderly patients, the incidence of lithium toxicity is $1.5 \%$ per year. ${ }^{11,12)}$ Our patient was 74 years of age and using multiple drugs including haloperidol, risperidone and sertraline; however, she was not taking diuretics, ACE inhibitors, or NSAIDs. Both antipsychotics and antidepressants are also known to increase the risk of lithium intoxication when used concomitantly. It has been reported that combination of lithium with haloperidol, risperidone or serotonin reuptake inhibitors (SSRI) may cause rare neurotoxicity, but it is not clear that the toxicity is induced whether by drug interaction or effect of a single drug alone. On the other hand, it has been reported in pharmacokinetic studies that these antipsychotics and SSRIs do not effect lithium disposition and the serum lithium levels could maintain in therapeutic concentrations in case of intoxication. ${ }^{13)}$ However, the serum lithium levels increased in our case. In addition, the patient has used haloperidol and risperidone for 5 years and sertraline for 4 years; but she did not have any neurotoxicity symptoms until the second day of moxifloxacin administration. Because of these reasons we focused on moxifloxacinlithium interaction instead of the other drugs.

Haloperidol, risperidone, sertraline, and moxifloxacin were all associated with prolongation of ECG-derived corrected QT interval. Combination of these drugs could increase the risk of QTc prolongation. However in our case there were no ECG abnormalities. ${ }^{14)}$

Although other factors such as dehydration, rigorous dieting or low salt intake, high fever, or history of anesthesia or major operation have been reported to cause lithium toxicity in elderly patients, no symptoms or examination results indicated such conditions in our patient.

Result of the Naranjo Adverse Drug Reaction Probability Scale in this case, indicated a 'probable' (score, 6) interaction between lithium and moxifloxacin. ${ }^{15)}$

Although serum lithium levels are useful indicators for toxicity, the severity of toxicity does not always correlate with the serum lithium concentrations. This is true especially in the elderly, in whom the symptoms frequently suggest a higher level of serum lithium than that actually present. In our patient, who had a $1.7 \mathrm{mEq} / \mathrm{L}$ serum lithium concentration, we may anticipate a mild toxicity, but her symptoms were indicative of moderate toxicity.

Despite many reports of lithium toxicity when the antibiotics are prescribed concurrently with lithium therapy, cases in conjunction with fluoroquinolone agents are rare.

Levofloxacin, a fluoroquinolone agent, has been reported to increase the serum lithium levels. When co-administered with lithium, levofloxacin has been reported to cause both renal impairment and toxicity. In addition, levofloxacin is shown to increase the serum lithium concentrations in rabbits without causing renal impairment. ${ }^{16,17)}$

To the best of our knowledge, there are no case reports of an interaction between lithium and moxifloxacin in the literature. Moxifloxacin is known to be a safe and well-tolerated fluoroquinolone antibiotic agent with a high patient adherence profile and is widely used in the elderly for the treatment of respiratory infections. ${ }^{9)}$ The interaction between levofloxacin and lithium interaction 
may be explained on the basis of excretion, because they are both excreted renally. It is suggested that levofloxacin decreases the excretion of lithium by decreasing its glomerular filtration or tubular secretion. Although the exact mechanism of the interaction between lithium and moxifloxacin is unclear, moxifloxacin could slow down the excretion of lithium by decreasing its glomerular filtration or tubular secretion, similar to levofloxacin. ${ }^{16,17)}$

Further studies on potential interaction between moxifloxacin and lithium are needed. Physicians who prescribed lithium should be careful for the possible drug interactions.

Also, considering these interactions on elderly patients receiving lithium is essential.

\section{REFERENCES}

1. Chung YK. Neuroprotective effects of lithium relevant to its therapeutic actions. Clin Psychopharmacol Neurosci 2008; 6:11-18.

2. Raja M, Raja S. Lithium treatment in elderly patients affected by mood disorders. Riv Psichiatr 2014;49:180-182.

3. Malhi GS, Tanious M, Das P, Berk M. The science and practice of lithium therapy. Aust N Z J Psychiatry 2012; 46:192-211.

4. Sproule B. Lithium in bipolar disorder: can drug concentrations predict therapeutic effect? Clin Pharmacokinet 2002;41:639-660.

5. Young W. Review of lithium effects on brain and blood. Cell Transplant 2009; 18:951-975.
6. Oruch R, Elderbi MA, Khattab HA, Pryme IF, Lund A. Lithium: a review of pharmacology, clinical uses, and toxicity. Eur J Pharmacol 2014;740:464-473.

7. Sproule BA, Hardy BG, Shulman KI. Differential pharmacokinetics of lithium in elderly patients. Drugs Aging 2000; 16:165-177.

8. Timmer RT, Sands JM. Lithium intoxication. J Am Soc Nephrol 1999;10:666-674.

9. Haussmann R, Bauer M, von Bonin S, Grof P, Lewitzka U. Treatment of lithium intoxication: facing the need for evidence. Int J Bipolar Disord 2015;3:23.

10. Stass H, Kubitza D. Profile of moxifloxacin drug interactions. Clin Infect Dis 2001;32 Suppl 1:S47-S50.

11. Juurlink DN, Mamdani MM, Kopp A, Rochon PA, Shulman KI, Redelmeier DA. Drug-induced lithium toxicity in the elderly: a population-based study. J Am Geriatr Soc 2004; 52:794-798.

12. Rej S, Herrmann N, Shulman K. The effects of lithium on renal function in older adults--a systematic review. J Geriatr Psychiatry Neurol 2012;25:51-61.

13. Finley PR. Drug interactions with lithium: an update. Clin Pharmacokinet 2016;55:925-41.

14. Beach SR, Celano CM, Noseworthy PA, Januzzi JL, Huffman JC. QTc prolongation, torsades de pointes, and psychotropic medications. Psychosomatics 2013;54:1-13.

15. Naranjo CA, Busto U, Sellers EM, Sandor P, Ruiz I, Roberts $\mathrm{EA}$, et al. A method for estimating the probability of adverse drug reactions. Clin Pharmacol Ther 1981;30:239-245.

16. Takahashi H, Higuchi H, Shimizu T. Severe lithium toxicity induced by combined levofloxacin administration. J Clin Psychiatry 2000;61:949-950.

17. Rajagopalan S, Shafiq N, Pandhi P, Malhotra S. Effect of levofloxacin on lithium - a pharmacokinetic study in rabbits. Fundam Clin Pharmacol 2013;27:181-185. 